\title{
Adolescents' evaluations of the quality of lifestyle counselling in school-based health care
}

\begin{abstract}
Background: Adolescents need effective lifestyle counselling precisely because health problems are so common. Good-quality lifestyle counselling can prevent the problems from becoming worse and decrease the costs of health care. Nurse practitioners in schools are well positioned to promote adolescent health.
\end{abstract}

Aim: This study describes adolescents' evaluations of the quality of lifestyle counselling and factors related to it in school-based health care.

Methods: The data were collected from seventh to ninth grade adolescents $(n=846)$ using the Counselling Quality Instrument, from two junior high schools in northern Finland. The study employed a web-based survey. Response rate was $67 \%(\mathrm{n}=563)$. The data were analysed via descriptive statistics.

Results: Most adolescents (84\%) reported that the counselling resources related to school-based health care are quite good. Most of them reported that nutrition (70\%) and physical activity (63\%) related to lifestyle counsellin are sufficient. Approximately half of adolescents $(51 \%)$ considered the counselling related to substance abuse as being sufficient. Most (80\%) felt that the level of interaction during counselling is good. Overall, the majority of adolescents reported that goaloriented lifestyle counselling (67\%) and adolescent-centred counselling (69\%) are good. Finally, most adolescents (72\%) reported that they have benefitted from lifestyle counselling. Gender and health status were significantly related to resources, interaction and benefits of lifestyle counselling. Girls evaluated that counselling were more adolescent-centred than boys. Adolescents with very good health status evaluated content of lifestyle counselling better than adolescents with poorer health status.

Conclusion: The adolescents evaluated the quality of lifestyle counselling in school-based health care as mainly being good. School nurses should pay particular attention when providing counselling to boys and those who are in poorer health.

Keywords: adolescent, lifestyle counselling, quality, school-based health care.

\section{Introduction}

Health promotion and lifestyle counselling are core elements of school nurses' work. School nurses are well positioned to promote adolescents' health because the most adolescents interact with a school nurse at least once a year [1]. In Finland, health care services in schools are statutory. The school nurse meets a certain number of students and health check-ups are conducted annually [2]. In junior high schools $\left(7^{\text {th }}\right.$ to $9^{\text {th }}$ grades), extensive health check-ups are conducted for students in the eighth grade, at which time parents are also invited to participate [3]. Health promotion in schools is done on an individual basis, but it also focuses on factors at the general level, such as the environment. School nurses provide for adolescents the lifestyle counselling as part of the health 
check-ups. [4.] Lifestyle counselling should be multi-professional with doctors and dietitians [1], evidence-based and of a high quality [5].

There is no generally accepted definition for good-quality lifestyle counselling in school health care settings. The definition for quality lifestyle counselling presented in this study is based on the existing model for good-quality counselling. Based on the model, the quality lifestyle counselling is understood as a method that is adolescent-centred, interactive and goal oriented; it is implemented with sufficient counselling content and appropriate resources and has positive benefits for adolescents. The definition includes four elements: resources, content, implementation and benefits of counselling. [6-12.]

School health care should have sufficient resources for lifestyle counselling and services should be delivered in line with quality standards. Appropriate materials must be available for providing the knowledge about healthy lifestyles for adolescents [13]. However, lifestyle counselling is not always effective due to school nurses having insufficient time for counselling and a lack of evidence-based knowledge and counselling skills [14].

Adolescents need the sufficient lifestyle counselling about content of nutrition, physical activity and substance use and abuse. Obesity, being overweight [15], insufficient physical activity [16] and sedentary behaviour [17] are common among adolescents. Substance abuse increases with age during adolescence $[1,18,19]$. Though adolescents' substance abuse has declined, abuse still have serious problems among adolescents [20]. Health-related risk behaviours in adolescents contribute to many leading causes of disease and social problems experienced during adolescence as well as adulthood [21]. Good quality counselling in school health care that targets adolescents' lifestyles is wholly appropriate as means to helping adolescents establish healthy lifestyles as they move forward into their adult years [5].

Counselling is mainly preventative in its influence on adolescents' health-related behaviours, such as knowledge, beliefs, skills, attitudes, values and support [22]. However, implementation of counselling should be interactive and goal-oriented and adolescent-centred. Counselling in the school health care setting is often implemented on individually with interaction between the school nurse and adolescent $[23,24]$. Nurses use verbal interaction approaches to promote adolescent's participation [24]. Confidence [25, 26], good interaction and a positive atmosphere are core elements of implementing good -quality lifestyle counselling. If adolescents trust in school nurse, they are more likely to discuss about their risk behaviour and sensitive issues [27]. Insufficient resources, such as a lack of time [7] and the negative attitudes of adolescents towards lifestyle counselling may impair interaction during counselling [28]. Lifestyle counselling should include goal setting according adolescents' needs. Also short and long term goals should be placed together with adolescent, if behavioural change is desired, for example in weight management [29]. Good lifestyle counselling should be targeted at an adolescent's particular developmental stage [28]. Moreover, it should take into account an adolescent's needs $[23,30]$ to be adolescent-centred.

Lifestyle counselling benefits adolescents by increasing their attitudes, knowledge [13] and motivating them to evaluate their own lifestyles [23] and adhere to lifestyles changes [13, 31]. Good-quality lifestyle counselling can prevent problems from becoming worse [32] and decrease the costs of health care [5]. However, little evidence of adolescents own perceptions about benefits of school based lifestyle counselling.

This study describes adolescents' evaluations of the quality of lifestyle counselling and factors related to it in school health care settings. To the best of our knowledge, adolescents' own 
evaluations of the quality of lifestyle counselling in school health care settings has not previously been studied.

\section{Material and Methods}

\section{Study design}

A cross-sectional, prospective design was used.

\section{Study population}

The sample $(n=846)$ consisted of all the adolescents $\left(7^{\text {th }}\right.$ to $9^{\text {th }}$ grades $)$ in two junior high schools in northern Finland, who were invited to participate in the survey in the fall of 2015. These schools selected for the study because they are socio-economically similar schools and both schools have students was approximately at the same amount. Returned questionnaires $(n=563)$ were completed acceptably and the response rate was $67 \%$.

\section{Questionnaire}

Data were collected using the Counselling Quality Instrument (CQI) (@ Kääriäinen 2007). The instrument has been tested for validity and reliability before in earlier studies [6-12]. The questionnaire was modified to fit a school-based health care context in cooperation with the original developer of the questionnaire. The modified questionnaire's content validity with respect to the CQI was assessed by four school nurses and, based on the evaluations, minor modifications were made to a few of the items in the questionnaire. The questionnaire was modifed by clarifying the items for adolescents so that they understand them. The CQI was piloted first with a small sample of adolescents $(n=17)$ to ensure its clarity. The construct validity of the questionnaire was tested using principal component analysis with Varimax rotation. Communalities varied between 0.46 and 0.90, whereas component analysis loadings ranged between 0.48 and 0.92 and demonstrated good construct validity for the questionnaire [33].

The CQI instrument consisted of seven background questions (Table 1) and 70 items measuring the quality of the lifestyle counselling. It covered the following areas: resources, for example school nurse's counselling skills, material use, nurse's attitude ( 7 items $)$. The content of the counselling, for example effects of nutrition, physical activity, sedentary behaviour, gaming and substance abuse to health in all aspects (37 items), how the counselling was implemented, for example atmosphere, understandable counselling, reciprocal interaction (22 items) and the benefits of the counselling, for example adherence to regimens, effects to adolescents attitudes and knowledge (4 items).

Respondents were asked to rank each of the items on a 5-point Likert-type scale $(1=$ totally agree and $5=$ totally disagree / I didn't need counselling). In addition, the questionnaire asked students to rate the quality of the counselling as very poor, poor, fair, good or excellent.

Insert Table 1 here

\section{Data collection}

The study was conducted via a web-based survey for adolescents during the school day by the school's staff and researchers. Before collecting the data, the school staff informed adolescents and their parents aboutthe study. Adolescents evaluated received lifestyle counselling based on their 
previous health check-up when they responded to the web-based survey. The school's staff or researchers shared a link to questionnaire and adolescents used computers or iPads with answering at school.

\section{Data analysis}

Data were analysed using SPSS Statistics 22.0 (IBM, Chicago, IL, USA). Descriptive statistics, such as frequencies, percentages, means and standard deviations, were used. All variables were evaluated for normality using the Kolmogorov-Smirnov test, and the variables were nonparametric. Background variables and previous health check-up, including the extent of the health check-up, were classified using a dichotomous scale. Three groups were formed based on the health status of the participants and four groups were formed based on their estimated weight.

Sum variables were constructed based on principal component analysis. A total of eight sum variables measuring the effects of lifestyle counselling were created. Counselling resources consisted of one sum variable, whereas the content of the counselling sessions consisted of three sum variables (nutrition, substance abuse and physical activity), how the counselling sessions were implemented consisted of three sum variables (interactive, goal-oriented and adolescent-centred counselling) and the benefits of counselling included one sum variable. The sum variables were verified using Cronbach's alpha values, which varied between 0.88 and 0.98 and demonstrated that the questionnaire had good internal consistency (Table 2). The sum variables were recorded into three categories to describe the quality of the counselling. The theoretical ranges and classification boundaries of the sum variables were on a scale ranging from 1 to 5: 1.00-2.49= good, 2.50-3.49= I can't tell and 3.50-5.00 = poor; for the content of the lifestyle counselling sessions, the scores were as follows: $1.00-2.49=$ sufficient, $2.50-4.00=$ insufficient and 4.01-5.00 = I didn't need counselling. Histogram and boxplot figures were used as the basis for the classification boundaries.

Statistical differences in the sum variables for the background variables were tested using the Mann-Whitney U-test and the Kruskall-Wallis test. If a statistically significant difference was discovered during the multiple group analysis, Mann-Whitney U test was performed to assess the pair of groups for which the difference was significant. Then, a Bonferroni correction was carried out for the $p$ value. [34.] The statistically significant limit value was $p<0.05$ when assigning differences between the groups [33].

Insert Table 2 here

\section{Ethical considerations}

The principles of the Helsinki Declaration were followed for the study [35]. Permission for the study was given by the education and health service managers as well as the school administrators. Written informed consent was obtained from the developer of the questionnaire. The school administrators were evaluated with respect to the normal operations of the school and the questionnaire did not directly collect identifying information about the adolescents. Therefore, the study was carried out without the consent of the parents. However, the parents were informed about the study through the school information system in advance. The adolescent were given written information about the study before they agreed to participate. [36.] A cover letter informed them about the study, its purpose, the respect for privacy, the voluntary nature of the study and its confidentiality [33]. Students decided for themselves whether they wanted to participate in the study after reading the information and agreeing to provide their written informed consent. 


\section{Results}

\section{Background characteristics}

Table 1 presents a summary of the participants' background characteristics. The study involved 563 adolescents: $46 \%$ were girls and 54\% were boy, and their mean was 14 years. Most of the adolescents reported that they had recently undergone a general health check-up. Most adolescents rated their health as very good, and felt that they were at a normal weight. Nineteen percent of students claimed that they were overweight or obese, and more than half of them $(63 \%$ overweight and $61 \%$ obese) reported that they had been trying to lose weight during the semester. The majority of respondents did not attempt to lose weight during the semester. Minority of parents participated to adolescents' health check-up.

\section{Quality of lifestyle counselling}

Most adolescents (84\%) evaluated that the resources allocated for counselling are good, whereas three percent felt that the resources are inadequate and the remaining 13\% could not say whether or not the resources are adequate (Figure 1). Evaluations differed to a statistically significantly based on gender $(\mathrm{p}=0.007)$. Boys $(\mathrm{Md} 1.57, \mathrm{SD} 0.91)$ reported that the resources are inadequate more often than girls (Md 1.43, SD 0.61). Adolescents' evaluations of available resources also varied based on their health status $(\mathrm{p}=0.001)$ (Table 3). Adolescents who reported that their health status were very good (Md 1.29, SD 0.85) reported that they were quite satisfied with the resources more often than adolescents with only a fairly good health status (Md 1.57, SD 0.72).

Insert Figure 1 here

Insert Table 3 here

The content of the counselling was measured in areas of nutrition, substance abuse and physical activity. Seventy percent of adolescents reported that the counselling related to nutrition was sufficient. Fifteen percent of adolescents stated that nutrition counselling was insufficient. The statistically significant differences between students were found with a very good health status and a fairly good health status $(\mathrm{p}=0.003)$ (Table 3$)$. Adolescents who reported their health status as very good (Md 1.69, SD 1.32) also stated that nutritional counselling was sufficient more often than the adolescents with only a fairly good health status (Md 2.00, SD 1.28). Approximately half of adolescents $(51 \%)$ considered the counselling related to substance abuse as sufficient, whereas roughly one-third of them (34\%) reported that they have not needed it. Fifteen per cent of the adolescents reported that substance abuse counselling was insufficient (Figure 2). No statistically significant differences were found between the background variables and substance abuse counselling. , $63 \%$ of the adolescents considered the physical activity counselling to be sufficient. Nineteen per cent of adolescents, however, reported that physical activity counselling was insufficient. Eighteen per cent of adolescents reported that they don't need the counselling related to physical activity (Figure 2). Adolescents' evaluations differed statistically significantly regarding their health status $(\mathrm{p}=0.042)$. However, after making pairwise comparisons with a Bonferroni correction, nony statistically significant differences found (Table 3).

Insert Figure 2 here

The implementation of lifestyle counselling was measured as interaction, goal-oriented and adolescent-centred counselling. Eighty per cent of adolescents reported that interaction during the 
counselling sessions was good. Four per cent adolescents felt that it was poor. Sixteen per cent of adolescents could not tell what kind of interaction they desired during counselling sessions (Figure 1). The evaluations differed statistically significantly between genders $(p=0.003)$ (Table 3). Girls (Md 1.33, SD 0.71) reported that the interaction during lifestyle counselling sessions was better more often than boys (Md 1.67, SD 0.98). Also adolescents with different health status evaluated the interaction differently $(\mathrm{p}=0.001)$. Adolescents with very good and fairly good health had statistically significant differences $(\mathrm{p}=0.001)$ (Table 3$)$. Adolescents with very good health status (Md 1.33, SD 0.93) reported that the interaction was good during counselling sessions more often than adolescents with only fairly good health (Md 1.67, SD 0.81). Most of adolescents (67\%) reported that goal-oriented lifestyle counselling was good, whereas $28 \%$ could not tell and $5 \%$ reported that it is poor (Figure 1). The background variables did not affect students' attitudes about goal-oriented lifestyle counselling. Most of adolescents (69\%) reported that the counselling was adolescent-centred. Twenty-five per cent could not say whether or not the lifestyle counselling was adolescent-centred and $6 \%$ of adolescents reported that the counselling was not adolescent-centred (Figure 1). Evaluations differed to a statistically significantly between genders $(p=0.017)$ (Table 3). Girls (Md 1.75, SD 0.83) reported more often than boys that the counselling sessions were adolescent-centred (Md 2.00, SD 0.98).

Most of the adolescents (72\%) reported that lifestyle counselling had benefits. Twenty-three per cent of adolescents could not tell whether lifestyle counselling has benefitted them or not. Five per cent of adolescents reported that the lifestyle counselling has not benefitted them at all (Figure 1). There were the statistically significant differences between genders concerning evaluations of counselling benefits $(\mathrm{p}=0.005)$ (Table 3). Girls $(\mathrm{Md} 1.50$, SD 0.85) reported more often than boys that they have benefitted from lifestyle counselling (Md 2.00, SD 1.03). Adolescents who had recently undergone general health check-ups reported that they have benefitted from it $(\mathrm{Md} 1.50$, SD 0.92) more often than adolescents whose last visit to the school nurse had been for an extended health check-up $(\mathrm{p}=0.004)(\mathrm{Md} 2.00, \mathrm{SD} 1.02)$. The health status was associated to benefits of lifestyle counselling $(\mathrm{p}=0.019)$. The main differences were between adolescents who reported that their health status was very good and those who reported a poor health status $(p=0.036)$ (Table 3$)$. Adolescents who reported that their health status was poor also stated that they have benefitted less from counselling (Md 3.00, SD 0.89) than did adolescents who reported that they were in very good health (Md 1.50, SD 1.01).

Overall, more than half of the adolescents (53\%) reported that the quality of lifestyle counselling in school-based health care programmes is, a whole, quite good.

\section{Discussion}

In this study, new information was obtained on adolescent's own evaluations of lifestyle counselling in school-based health care services. Boys and adolescents who reported their health status as poor evaluated the lifestyle counselling in school-based health care worse than the other adolescents. Most adolescents reported that lifestyle counselling in school-based health care was of a good quality, but they also found needs for improvement. The role of the school nurse in supporting lifestyle changes and promoting health is important [37].

The school nurse counsels adolescents with different background and diseases [1]. Nurses have reported lack of time and counselling skills, when counselling adolescents with chronic diseases e.g. type II diabetes [38]. In this study, those adolescents who rated their health status as poor also gave poor marks for the quality of lifestyle counselling with respect to counselling resources, sufficient nutritional content, interaction and benefits of the counselling. Previous studies have reported that 
the school nurse does not adequately take into account the starting points of the various adolescents in the lifestyle counselling sessions [39]. Also, a study by Kääriäinen [6] demonstrated that physical, mental, social and other environmental factors should be taken into account when counselling students. The school nurse should pay attention to an adolescent's background (gender and health status). The school nurse has a good opportunity to have a particular effect on the health and well-being of adolescent girls [26], while boys are more hesitant to seek out school-based health care services $[31,40]$ because they are afraid of being perceived as weak or are afraid of being bullied [40].

The duration and content of the more extensive health check-up are more comprehensive than the general heath check-up. Surprisingly, we found that adolescents who had had the general check-up rated the benefits of lifestyle counselling more highly than adolescents who had had an extensive health check-ups. Extensive health check-up includes more measurements (e.g. hearing, seeing, blood pressure) and examine the whole family well-being, than general check-up. It may be that there is little time left for counselling. And adolescents therefore evaluate that the benefits of lifestyle counselling are worse in extensive health check-ups. In this study, the parents chose not to participate much in the extensive health check-ups for adolescents. However, parents' participation in adolescents' lifestyle counselling is important because they offer support and provide motivation [41].

Adolescents also have different kinds of counselling needs. In this study, adolescents needed more counselling for nutrition and physical activity than for substance abuse. Most adolescents rated the nutrition and physical activity lifestyle counselling as good. But almost one out of five stated that the physical activity counselling was insufficient. In study of Grimstvedt et al. [42] argued that nurse practitioners knowledge of physical activity counselling is good, but they are interested in receiving training for that. Overall, promoting physical activity is challenging, and the effects are small based on prior meta-analysis [29, 43]. According to Golsäter et al. [24], the school-based health care health topics of discussion most commonly are lifestyles, nutrition and physical activity. The informational content and guidelines provided to school nurses engaged in counselling is often insufficient [39]. In this study, the adolescents reported that the contents of the counselling sessions are for the most part sufficient, but we did discover differences in perception based on the reported health status of the various students. Interestingly, one-third of the adolescents who took part in the study did not needed counselling related to substance abuse, even though adolescents do suffer from substance abuse problems [44, 45]. In Finland, the use of substances is still low at the beginning of junior high school, but it will increase as the adolescents continue to grow [46]. In this study, $41 \%$ of the participants were in $7^{\text {th }}$ grade, which may partly explain this result. Typically, boys use more alcohol than girls [47].

In this study, participants rated the implementation of lifestyle counselling as good in school-based health care as a whole. In particular, the girls reported preferring it more than the boys. They reported that the level of interaction is good during counselling sessions, which supports the findings presented in earlier studies [6-12]. Adolescents reported that they trust the school nurse and feel that they have been listened to [48]. In this study, students reported that goal-oriented and adolescent-centred counselling require further development. Even still, most reported feeling that the counselling is for the most part adolescent-centred and private and that the nurse does not judge them. The barriers hindering participation in school counselling include a lack of knowledge about the services and adolescents feeling embarrassed that their problems are not considered to be private. [31.] The extent to which school nurses promote the health of adolescents requires more flexibility so as to create a confidential relationship between the adolescent and the school nurse. A relationship of trust with the school nurse can better promote the needs of adolescents. [30.] It is 
important that nurses receive adequate education regarding how best to provide good-quality lifestyle counselling. Kääriäinen and Kyngäs [8] also obtained similar results regarding the need to re-educate health personnel. School nurses also need more evidence-based knowledge and new techniques for evaluating their work [4]. In the future, school nurses should receive more education in how to provide lifestyle counselling and cooperate more with other professionals, such as dietitians, in order to provide better lifestyle counselling [39].

Adolescents participating to this study evaluated the benefits of lifestyle counselling. Also in earlier studies, adolescents reported that lifestyle counselling has had a positive effect on their health and well-being [49, 31]. In addition, earlier interventions in school-based health care have proven to be effective [5]. Effective lifestyle counselling should support adolescents in re-evaluating their lifestyle choices [23]. Adolescent obesity and being overweight in general have increased in recent years [15], and therefore there is a tremendous need for effective counselling on how to prevent obesity among adolescents [5]. In this study, adolescents' opinions about their weight were not statistically significantly associated with the quality of the lifestyle counselling. Previous research has suggested that lifestyle counselling by the school nurse has positively affected the health behaviour of obese adolescents, but not their BMI [50]. However, the school nurse is crucial in preventing and treating obesity among adolescents.

\section{Study limitations}

The strengths of the study lie in the fact that the data was collected using a recognised instrument with a high rate of validity and reliability $[7,8]$. Experts in nursing and nursing science evaluated the content validity during each session. The questionnaire was piloted with the junior high school students. The sufficiency of the data and the usability of the correlation matrix for the principal component analysis was tested using Bartlett's test $(\mathrm{p}<0.001)$ and the Kaiser-Meyer-Olkin test $(\mathrm{p}$ $>0.60$ ). In this study, the principal component analysis indicated good construct validity, whereas the Cronbach's alpha values ranged between 0.88 and 0.98 and demonstrated high internal consistency $[33,51]$.

The response rate was $67 \%$, which was good [33]. However, some limitations affect the generalisability of the findings of this study. The sample represented health care in two schools in Finland. An effort was made to minimise the number of nonresponses via a covering letter, the layout of the questionnaire and a web-based survey. None of the questionnaires were rejected. Only $25 \%$ of the adolescents included in the study were in the $8^{\text {th }}$ grade. This might have been influenced by the timing of the data collection and the means of recruitment. The validity of the study may also have been weakened by the fact that the adolescents evaluated their previous health check-up, which could have occurred more than a year ago and, consequently, they may not have remembered them so well. In the study, the standard deviation for responses to questions regarding the 'content of the lifestyle counselling' was quite large. This may be due to the fact that some adolescents does not feel they need lifestyle counselling. On the other hand, the statistical significance might be due to the rather large size of the sample.

\section{Conclusion}

According to our findings, the adolescents rated the quality of lifestyle counselling in school-based health care as mainly being good. In lifestyle counselling, the adolescents' health status should be better studied in order to find out what kind of lifestyle counselling she or he needs. This would improve results. School nurses should pay particular attention when providing counselling to boys and those who are in poorer health. The role of the extensive health check-ups should be taken into 
account when considering the quality of lifestyle counselling. Based on our findings, the school nurses should work to improve goal-oriented and adolescent-centred lifestyle counselling.

\section{Practice Implications}

The study provides information regarding the quality of lifestyle counselling in school-based health care. Lifestyle counselling should, in the future, pay more attention to the adolescents' backgrounds, gender and health status. Results can be used to develop school-based lifestyle counselling more from the adolescents' perspective. School-based health care should be able to guarantee that sufficient resources are allocated for providing good-quality lifestyle counselling. School nurses need to update their knowledge in order to provide evidence-based counselling, and this in turn will also affect the quality of the lifestyle counselling.

\section{Acknowledgements}

We thank the participants for their contribution to the study.

\section{Author contributions}

Laura Myllymäki, Heidi Ruotsalainen and Maria Kääriäinen designed the study. Laura Myllymäki and Heidi Ruotsalainen collected the data. Laura Myllymäki performed statistical analysis. Laura Myllymäki and Heidi Ruotsalainen drafted the manuscript. Heidi Ruotsalainen and Maria Kääriäinen performed critical revisions for important intellectual content.

\section{Ethical approval}

The study was approved by the management of the involved organisations. Research ethical guidelines were followed.

\section{Funding}

No external funding.

\section{References}

1 Murray RD, Devore CD, Gereige RS, Grant LM, Roland MM, Lamont JH, Monteverdi GJ, Wheeler LSM, Pattishall III EG, Magalnick H. The Role of the School Nurse in Providing School Health Services. J Sch Nurs 2008; 24: 269-74.

2 Finnish health service act, 1326/2010, http://www.finlex.fi/en/laki/kaannokset/2010/en20101326.pdf (last accessed 9 February 2016).

3 Government decree prenatal care, school and student health care as well as children and young people in preventive oral health (Finnish), 338/2011, http://www.finlex.fi/fi/laki/alkup/2011/20110338 (last accessed 9 February 2016).

4 Reuterswärd M, Lagerström M. The aspects school health nurses find important for successful health promotion. Scand J Caring Sci 2010; 24: 156-63. 
5 Langford R, Bonell C, Jones H, Pouliou T, Murphy S, Waters E, Komro K, Gibbs L, Magnus D, Campbell R. The World Health Organization's Health Promoting Schools framework: a Cochrane systematic review and meta-analysis. BMC Public Health 2015; 130: $1-15$.

6 Lipponen K, Kyngäs H, Kääriäinen M. Surgical nurses readiness for patient counseling. J Orthop Nurs 2006; 10: 221-7.

7 Kääriäinen M. The Quality of Counselling: The Development of a Hypothetical Model (Finnish). Acta Universitatis Ouluensis D 937. Oulu: Oulu University Press. 2007.

8 Kääriäinen $\mathrm{M}$, Kyngäs $\mathrm{H}$. The quality of patient education evaluated by the health personnel. Scand J Caring Sci 2010; 24: 548-56.

9 Kääriäinen M, Kukkurainen ML, Kyngäs H, Karppinen L. Improving the quality of rheumatoid arthritis patients' education using written information. Musculoskeletal Care 2011; 9: 19-24.

10 Kaakinen P, Kääriäinen M, Kyngäs H. The chronically ill patients' quality of counseling in the hospital. J Nurs Educ and Pract 2012; 2: 114-23.

11 Kaakinen P, Kyngäs H, Kääriäinen M. Predictors of good-quality counselling from the perspective of hospitalised chronically ill adults. J Clin Nurs 2013; 22: 2704-13.

12 Kajula O, Kääriäinen M, Moilanen J, Kyngäs H (2015) The quality of genetic counseling and connected factors as evaluated by male BRCA1/2 mutation carriers in Finland. J Genet Couns 2015. doi 10.1007/s10897-015-9885-x.

13 WHO 2015 Core competencies in adolescent health and development for primary care providers. http://apps.who.int/iris/bitstream/10665/148354/1/9789241508315_eng.pdf (last accessed 29 September 2016).

14 Burke L, Fair J. Promoting prevention: skill sets and attributes of health care providers who deliver behavioral interventions. J Cardiovasc Nurs 2003; 18: 256-66.

15 Ogden CL, Carrol MD, Kit BK, Flegal KM. Prevalence of childhood and adult obesity in the United States, 2011-2012. JAMA 2014; 311: 806-14.

16 Ekelund U, Tomkinson G, Armstrong N. What proportion of youth are physically active? Measurement issues, levels and recent time trends. Br J Sports Med 2011; 45: 859-65. doi:10.1136/bjsports-2011-090190.

17 Dias P, Domingis I, Ferreira M, Muraro A, Sichieri R, Goncalves-Silva R. Prevalence and factors associated with sedentary behavior in adolescents. Rev Saude Publica 2014; 48: 266-74.

18 Hibell B, Guttormsson U, Ahlström S, Balakireva O, Bjarnason T, Kokkevi A, Kraus L. The 2011 ESPAD Report. Substance Use Among Students in 36 European Countries. The 
Swedish Council For Information on Alcohol and Other Drugs. 2012, Stockholm, Sweden, http://www.espad.org/uploads/espad_reports/2011/the_2011_espad_report_full_2012_10_2 9.pdf (last accessed 15 February 2016).

19 Johnston LD, O'Malley PM, Miech RA, Bachman JG, Schulenberg JE. Monitoring the Future National Survey Results on Drug Use: 1975-2013: Overview, Key Findings on Adolescent Drug Use. Institute for Social Research. 2014, University of Michigan, Ann Arbour, http://www.monitoringthefuture.org/pubs/monographs/mtf-overview2014.pdf (last accessed 15 February 2016).

20 Torikka A, Kaltiala-Heino R, Luukkaala T, Rimpelä A. Trends in alcohol use amonf adolescents from 2000 to 2011: The role of socioeconomic status and depression. Alcohol and alcoholism 2016: 1-8 http://dx.doi.org/10.1093/alcalc/agw048

21 Center for Disease Control and Prevention (CDC). Physical activity and health. 2015, http://www.cdc.gov/physicalactivity/basics/pa-health/ (last accessed 2 march 2016).

22 Stewart-Brown S. What is the evidence on school health promotion in improving health or preventing disease and, specifically, what is the effectiveness of the health promoting schools approach? 2006, Copenhagen, WHO Regional Office for Europe, Health evidence network report, http://www.euro.who.int/document/e88185.pdf (last accessed 17 February 2016).

23 Golsäter M, Sidenvall B, Lingfors H, Enskär K. Adolescents' and school nurses' perceptions of using a health and lifestyle tool in health dialogues. J Clin Nurs 2011; 20: 2573-83.

24 Golsäter M, Lindfors H, Sidenvall B, Enskär K. Health dialogues between pupils and school nurses: a description of the verbal interaction. Patient Educ Couns 2012; 89: 260-6.

25 Lee RL. The role of school nurses in delivering accessible health services for primary and secondary school students in Hong Kong. J Clin Nurs 2011; 20: 2968-77.

26 Larsson M, Björk M, Ekebergh M, Johansson Sundler A. Striving to make a positive difference: school nurses' experiences of promoting the health and well-being of adolescent girls. J Sch Nurs 2014; 30: 358-65.

27 Klein J, Wilson K. Delivering quality care: adolescents' discussions of health risks with their providers. Journal of Adolescent Health 2002; 30:190-195.

28 Flattum C, Friend S, Story M, Neumark-Sztainer D. Evaluation of an individualized counseling approach as part of a multicomponent school-based program to prevent weightrelated problems among adolescent girls. J Am Diet Assoc 2011; 111: 1218-23.

29 Ruotsalainen H, Kyngäs H, Tammelin T, Kääriäinen M. Systematic review of physical activity and exercise interventions on body mass indices, subsequent physical activity and 
psychological symptoms in overweight and obese adolescents. $J$ Adv Nurs 2015; 71: 246177.

30 Wong EM, Cheng MM. Effects of motivational interviewing to promote weight loss in obese children. J Clin Nurs 2013; 22: 2519-30.

31 Banfield M, McGorm K, Sargent G. Health promotion in schools: a multi-method evaluation of an Australian school youth health nurse program. BMC Nurs 2015; 14: 1-11.

32 Brobeck E, Bergh H, Odencrants S, Hildingh C. Lifestyle advice and lifestyle change: to what degree does lifestyle advice of healthcare professionals reach the population, focusing on gender, age and education? Scand J Caring Sci 2015; 29: 118-25.

33 Polit DF, Beck CT. Nursing research: Generating and assessing evidence for nursing practice. 2012, Wolters Kluwer Health/Lippincott Williams \& Wilkins, Philadelphia.

34 Munro BH. Statistical methods for health care research. 2005, Lippincott Williams \& Wilkins, Philadelphia.

35 World Medical Association. WMA Declaration of Helsinki-Ethical principles for medical research involving human subjects. 2013,

http://www.wma.net/en/30publications/10policies/b3/index.html (last accessed 20 February 2016).

36 Finnish Advisory Board on Research Integrity. Ethical principles of research in the humanities and social and behavioural sciences and proposals for ethical review. 2009, http://www.tenk.fi/sites/tenk.fi/files/ethicalprinciples.pdf (last accessed 12 May 2015).

37 Fritsch K, Heckert KA. Working together: health promoting schools and school nurses. Asian Nurs Res 2007; 1: 147-52.

38 Jansink R, Braspenning J, van der Weijden T, Elwyn G, Grol R. Primary care nurses struggle with lifestyle counseling in diabetes care: a qualitative analysis. BMC Family Practice 2010; 11: 41. doi:10.1186/1471-2296-11-41.

39 Magnusson MB, Kjellgren KI, Winkvist A. Enabling overweight children to improve their food and exercise habits - school nurses' counselling in multilingual settings. J Clin Nurs 2012; 21: 2452-60.

40 Hutchinson L, St John W. Creating connections: Strategies to improve adolescent boys' access and engagement with school-based health services. Contemp Nurse 2012; 40: 25868.

41 Doyle AC, Goldschmidt A, Huang C, Winzelberg AJ, Taylor CB, Wilfley DE. Reduction of overweight and eating disorder symptoms via the internet in adolescents: a randomized controlled trial. J Adolescent Health 2008; 43: 172-9. 
42 Grimstvedt ME, Der Ananian C, Keller C, Woolf K, Sebren A, Ainsworth B. Nurse practitioner and physician assistant physical activity counseling knowledge, confidence and practices. Prev Med 2012; 54: 306-8.

43 Metcalf B, Henley W, Wilkin T. Effectiveness of intervention on physical activity of children: Systematic review and meta-analysis of controlled trials with objectively measured outcomes (EarlyBird 54). BMJ 2012; 345: e5888. doi: http://dx.doi.org/10.1136/bmj.e5888.

44 Pirskanen M, Pietilä A-M, Halonen P, Laukkanen E. School health nurses and substance use among adolescents-towards individual identification and early intervention. Scand J Caring Sci 2006; 20: 439-47.

45 Jensen CD, Cushing CC, Aylward BS, Craig JT, Sorell DM, Steele RG. Effectiveness of motivational interviewing interventions for adolescent substance use behavior change: a meta-analytic review. J Consult Clin Psychol 2011; 79: 433-40.

46 Kinnunen JM, Pere L, Lindfors P, Ollila H, Rimpelä A. Adolescent health and lifestyle survey 2015, the adolescent use of tobacco products and drugs. (Finnish). 2015, Reports of the Ministry of Social Affairs and Health series no 31, Helsinki.

47 Piko BF, Varga S, Wills TA. A study of motives for tobacco and alcohol use among high school students in Hungary. J Community Health 2015; 40: 744-9.

48 Bannink R, Broeren S, Heydelberg J, van't Klooster E, van Baar C, Raat H. Your Health, an intervention at senior vocational schools to promote adolescents' health and health behaviors, Health Educ Res 2014; 29: 773-85.

49 Chen MY, Chou CC, Hsu CY. The experiences of overweight female adolescents after health promotion counseling. J Nurs Res 2005; 13: 41-8.

50 Pbert L, Druker S, Gapinski MA, Gellar L, Magner R, Reed G, Schneider K, Osganian S. A school nurse-delivered intervention for overweight and obese adolescents. J Sch Health 2013; 83: 182-93.

51 Burns N, Grove SK. The practice of nursing research: conduct, critique, and utilization. 2005, Elsevier Saunders, Philadelphia. 
Table 1. Background variables of the participants $(n=563)$

\begin{tabular}{lll}
\hline & $\mathrm{n}$ & $\%$ \\
\hline Gender & 257 & 46 \\
$\quad$ Girl & 306 & 54 \\
$\quad$ Boy & 232 & 41 \\
Grade & 138 & 25 \\
$\quad$ 7.grade & 193 & 34 \\
8.grade & & \\
9.grade & 212 & 38 \\
Previous health check-up & 351 & 62 \\
$\quad$ Extensive health check-up & \\
$\quad$ General health check-up & & \\
Involvement of parents in the & & 12 \\
previous health check-up & 66 & 88 \\
$\quad$ Yes & 497 & \\
$\quad$ No & & 56 \\
Health status & 316 & 42 \\
$\quad$ Very good & 238 & 2 \\
Fairly good & 9 & \\
$\quad$ Poor & & 5 \\
Estimate weight & 29 & 76 \\
$\quad$ Underweight & 430 & 15 \\
Normal weight & 81 & 4 \\
Overweight & 23 & 22 \\
$\quad$ Obesity & 125 & 78 \\
Weight loss during this semester & & \\
$\quad$ Yes & 438 & \\
No & & \\
\hline
\end{tabular}


Table 2. Lifestyle counselling elements, Cronbach's alpha and indicators

\begin{tabular}{llcccc}
\hline Elements & Sum variables & $\begin{array}{c}\text { Number of } \\
\text { items }\end{array}$ & $\begin{array}{c}\text { Cronbach } \\
\text { alpha }\end{array}$ & Median* & SD** \\
\hline $\begin{array}{l}\text { "Resources of } \\
\text { lifestyle counselling" }\end{array}$ & Possibility of activity & 7 & 0.91 & 1.43 & 0.80 \\
\hline "Content of lifestyle & Nutrition & 13 & 0.98 & 2.00 & 1.30 \\
counselling" & $\begin{array}{l}\text { Substance abuse } \\
\text { Physical activity }\end{array}$ & 8 & 0.88 & 2.25 & 1.69 \\
\hline "Implementation of & Interaction of counselling & 9 & 0.98 & 2.00 & 1.32 \\
lifestyle counselling" & goal-oriented of counselling & & 0.96 & 1.44 & 0.88 \\
& Adolescent-centered & 9 & 0.95 & 2.00 & 0.93 \\
\hline "Benefits of lifestyle & Adherence & 4 & 0.88 & 2.00 & 0.92 \\
\hline counselling" & & 4 & 0.92 & 1.75 & 0.96
\end{tabular}

*Scale 1-5, where 1 totally agree -5 totally disagree / I didn't need counselling

**Standard deviation 
Table 3. Background variables contact sum variables the quality of lifestyle counselling

\begin{tabular}{|c|c|c|c|c|c|c|c|c|}
\hline \multirow{2}{*}{$\begin{array}{l}\text { The quality of lifestyle } \\
\text { counselling elements }\end{array}$} & \multirow{2}{*}{$\begin{array}{l}\begin{array}{l}\text { Resources of } \\
\text { lifestyle } \\
\text { counselling }\end{array} \\
p\end{array}$} & \multicolumn{3}{|c|}{ Content of lifestyle counselling } & \multicolumn{3}{|c|}{ Implementation of lifestyle counselling } & \multirow{2}{*}{\begin{tabular}{l}
$\begin{array}{l}\text { Benefits of } \\
\text { lifestyle } \\
\text { counselling }\end{array}$ \\
\multicolumn{1}{c}{$p$}
\end{tabular}} \\
\hline & & Nutrition & $\begin{array}{c}\text { Substance } \\
\text { abuse }\end{array}$ & $\begin{array}{l}\text { Physical } \\
\text { activity }\end{array}$ & Interaction & $\begin{array}{c}\text { Goal- } \\
\text { oriented }\end{array}$ & $\begin{array}{l}\text { Adolescent- } \\
\text { centered }\end{array}$ & \\
\hline Gender & $\begin{array}{c}p \\
0.007^{\mathrm{a}}\end{array}$ & $\begin{array}{c}\mathrm{p} \\
0.283^{\mathrm{a}}\end{array}$ & $\frac{p}{0.096^{a}}$ & $\frac{p}{0.442^{\mathrm{a}}}$ & $\begin{array}{c}p \\
0.003^{a}\end{array}$ & $0.266^{\mathrm{a}}$ & $\begin{array}{c}\mathrm{p} \\
0.017^{\mathrm{a}}\end{array}$ & $\begin{array}{c}p \\
0.005^{a}\end{array}$ \\
\hline $\begin{array}{l}\text { Previous health check- } \\
\text { up }\end{array}$ & $0.367^{\mathrm{a}}$ & $0.710^{\mathrm{a}}$ & $0.215^{\mathrm{a}}$ & $0.776^{\mathrm{a}}$ & $0.969^{\mathrm{a}}$ & $0.381^{\mathrm{a}}$ & $0.853^{\mathrm{a}}$ & $0.004^{a}$ \\
\hline Health status & $0.001^{b}$ & $0.001^{b}$ & $0.544^{b}$ & $0.042^{b}$ & $0.001^{b}$ & $0.050^{\mathrm{b}}$ & $0.077^{b}$ & $0.019^{b}$ \\
\hline $\begin{array}{l}\text { Very good- } \\
\text { fairly good }\end{array}$ & $0.001^{c}$ & $0.003^{c}$ & & $0.146^{c}$ & $0.001^{c}$ & & & $0.382^{c}$ \\
\hline Very good- Poor & $0.160^{c}$ & $0.122^{c}$ & & $0.228^{c}$ & $0.202^{c}$ & & & $0.036^{c}$ \\
\hline fairly good-Poor & $0.912^{c}$ & $0.676^{c}$ & & $0.614^{c}$ & $1.000^{c}$ & & & $0.102^{c}$ \\
\hline Estimate weight & $0.698^{b}$ & $0.930^{\mathrm{b}}$ & $0.423^{b}$ & $0.754^{b}$ & $0.525^{b}$ & $0.425^{b}$ & $0.818^{b}$ & $0.279^{b}$ \\
\hline
\end{tabular}

${ }^{\mathrm{a}}$ Mann-Whitney U -test, ${ }^{\mathrm{b}}$ Kruskall-Wallis test, ${ }^{\mathrm{c}}$ Pairwise Comparisons, with Bonferroni correction 


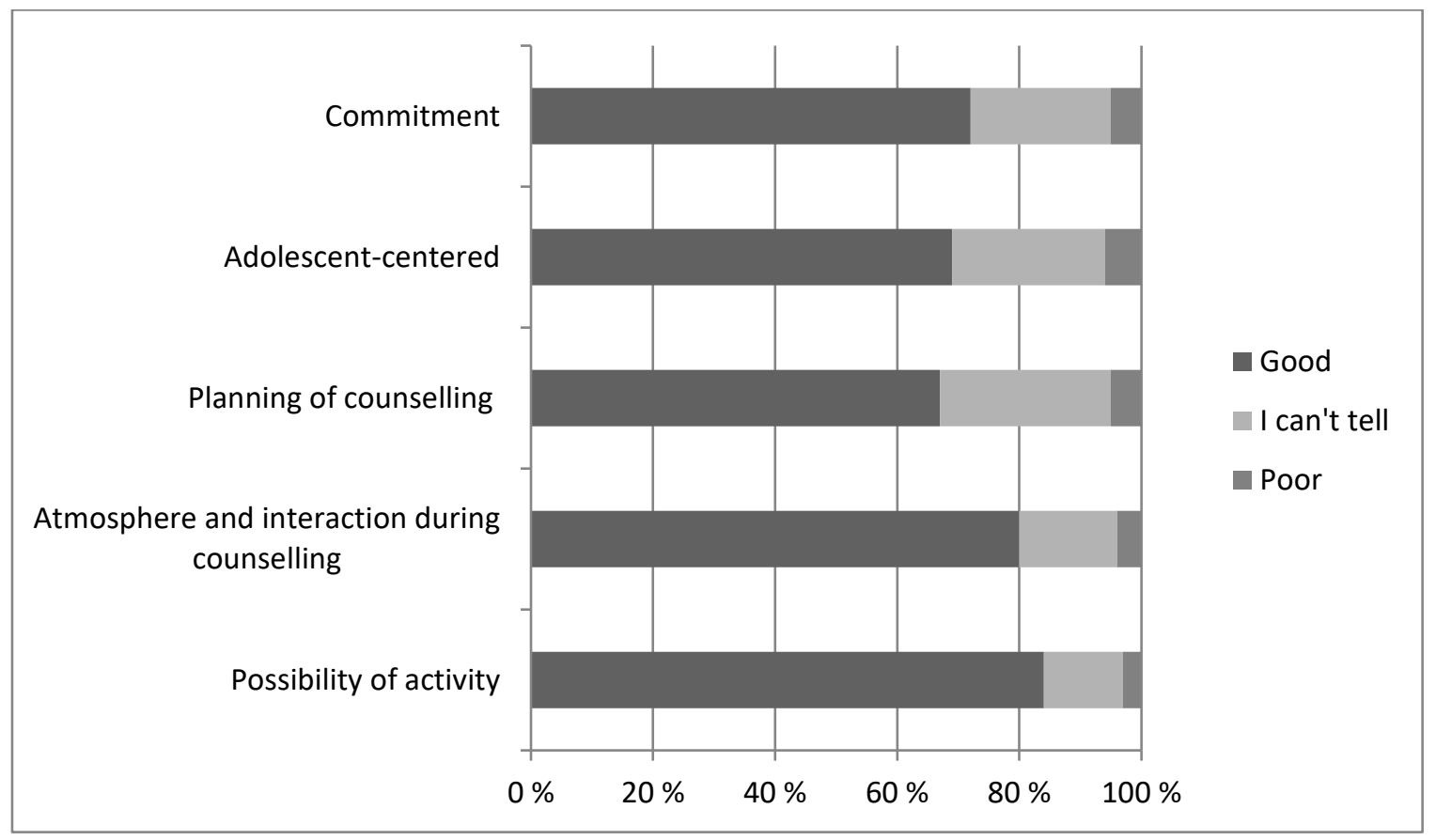

Figure 1. Division, by percentage, of lifestyle counselling based on the available lifestyle counselling resources, how the lifestyle counselling was implemented and the benefits of the lifestyle counselling for the adolescents $(n=563)$ being evaluated.

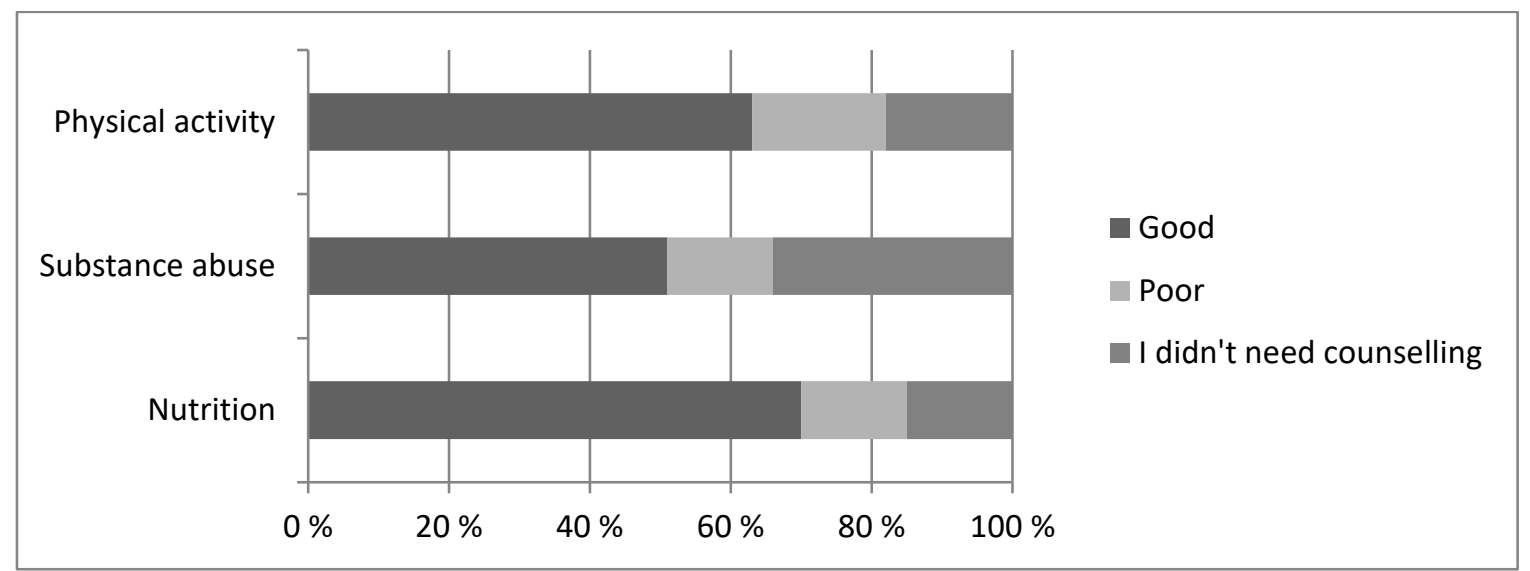

Figure 2, Division, by percentage, of lifestyle counselling based on the content of the lifestyle counselling for the adolescents $(n=563)$ being evaluated. 